\title{
Manufacturing and Coating by Kinetic Energy Metallization
}

\section{LDRD FY97 Final Report 97-ERD-067}

\section{Sang-Wook Kang}

February 9, 1998

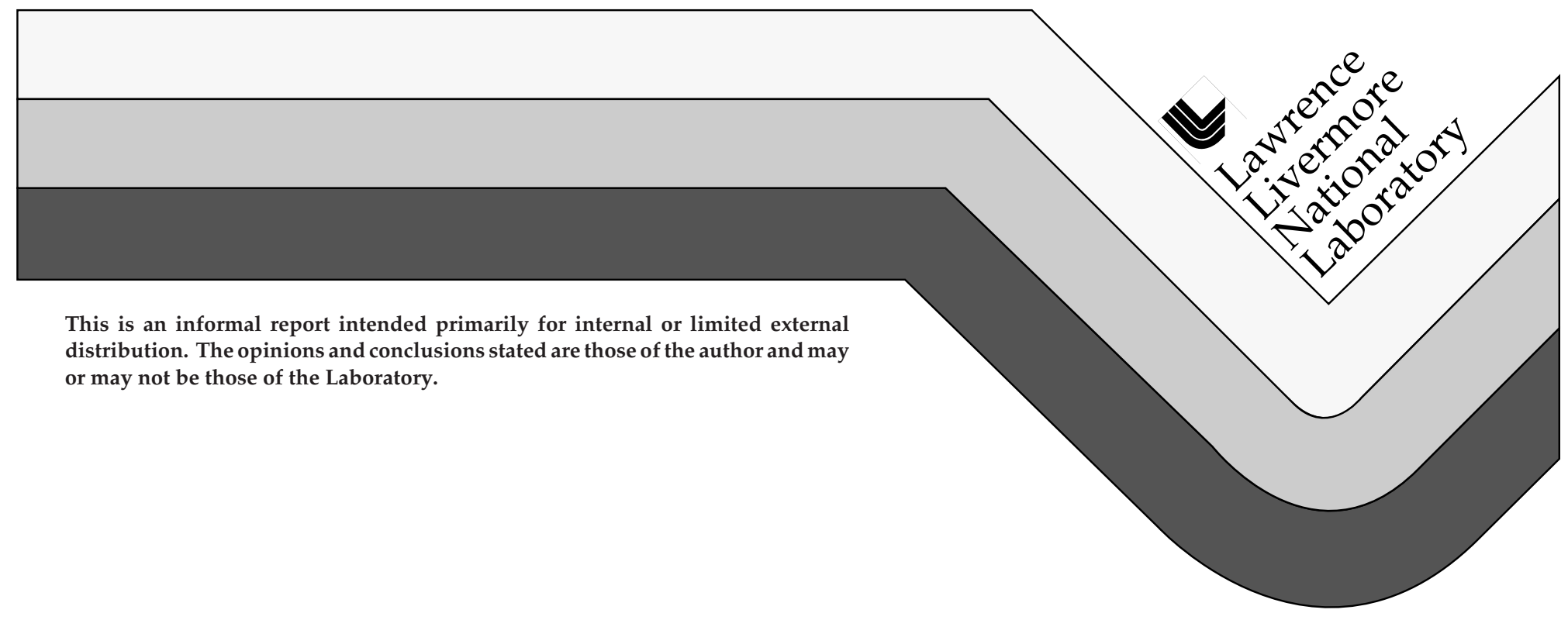




\section{DISCLAIMER}

This document was prepared as an account of work sponsored by an agency of the United States Government. Neither the United States Government nor the University of California nor any of their employees, makes any warranty, express or implied, or assumes any legal liability or responsibility for the accuracy, completeness, or usefulness of any information, apparatus, product, or process disclosed, or represents that its use would not infringe privately owned rights. Reference herein to any specific commercial product, process, or service by trade name, trademark, manufacturer, or otherwise, does not necessarily constitute or imply its endorsement, recommendation, or favoring by the United States Government or the University of California. The views and opinions of authors expressed herein do not necessarily state or reflect those of the United States Government or the University of California, and shall not be used for advertising or product endorsement purposes.

This report has been reproduced directly from the best available copy.

Available to DOE and DOE contractors from the Office of Scientific and Technical Information

P.O. Box 62, Oak Ridge, TN 37831

Prices available from (615) 576-8401, FTS 626-8401

Available to the public from the

National Technical Information Service

U.S. Department of Commerce 5285 Port Royal Rd.,

Springfield, VA 22161 


\title{
Manufacturing and Coating by Kinetic Energy Metallization
}

\author{
by Sang-Wook Kang
}

\section{PURPOSE}

To theoretically model the underlying metal-coating phenomena when metal particles impact a metal surface at high velocities under room temperature conditions.

\section{ANALYSIS}

\section{A. BACKGROUND}

A novel metal-coating method called Kinetic Energy Metallization (KEM) has been the subject of interest due to its promise of convenience, efficiency and economy. The convenience stems from a relatively simple equipment setup involving a particle feeder and a high-pressure plenum chamber with a supersonic nozzle.

The efficiency of the method has been demonstrated in laboratory tests at the Innovative Technology, Inc. (ITI), where the coating rates for such metals as copper onto an aluminum surface were measured to be several millimeters in a matter of minutes. The cost-saving economy over the current technology is derived from the KEM method being successful under ordinary room temperatures, i.e., the coating operation does not require any heating or phase changes on the part of the metal particles or the target materials.

Previous modeling analyses to understand the laboratory-demonstrated validity of the KEM method have been concerned with the dominant factors involved, i.e., in FY96 the high velocity of the impacting particles has been identified as a major component in effecting particle adhesion at the surface. The effects of the impact velocity have been computationally modeled on the two-dimensional hydrodynamics code called CALE. The calculated results indeed demonstrate the importance of the magnitude of the impact velocity by the induced transient deformation and stress waves traveling inside both the impinging particles and the target material following impact.

For current FY97, we have extended the theoretical modeling effort by proposing an adhesion threshold criterion involving surface energies and the 
interface stresses. In addition we made the first step in ascertaining the validity of the proposed bonding model by performing numerical calculations.

\section{B. PROPOSED ADHESION MODEL}

The metal-adhesion model relevant to the KEM method has four aspects, all involving timewise variations in the physical parameters: plastic deformation of the metal particles and targets upon impact; lateral displacement of the materials due to shear; increased contact surface area; and overcoming the adhesion energy barrier. When any of these four factors are absent the adhesion/bonding does not take place.

Plastic Deformation: This phenomenon occurs due to the high velocity -and hence high kinetic energy -- of the incident metal particles. This has been amply demonstrated in the test specimens obtained for the metals studies such as aluminum, copper, titanium and brass. For instance, plastic deformation was observed prominently when the plenum pressure was 2.8 MPa (approx. $400 \mathrm{psi}$ ) and the carrier gas was helium for copper particles of 10 micrometer mean diameter size impacting an aluminum target in helium. In this case the nozzle exit Mach number for helium was 3.5 corresponding to a $1750 \mathrm{~m} / \mathrm{s}$ gas velocity. When the plenum pressure was reduced to $0.7 \mathrm{MPa}(100 \mathrm{psi})$, however, there was very little plastic deformation and consequently no coating.

Computations on the CALE code have also been performed to determine the extent of plastic deformations following the particle impact for a range of impact velocities. For example, when the impact velocity for a 100-micron copper particle is $1,000 \mathrm{~m} / \mathrm{s}$, the deformation is pronounced, while a $200 \mathrm{~m} / \mathrm{s}$ velocity produces only a very small deformation. This has implication for the second aspect of the adhesion process, i.e., the lateral displacement of the materials with time following the impact.

Lateral Displacement due to Shear: The impact of the particles induces various stress waves that travel with time inside the materials. In particular, the shear stress causes a lateral displacement of the materials, both the incident and the target..

Increased Contact Surface Area: As a consequence of the lateral movement of the materials described above, the contact surface area has now been increased. This process must now overcome the resistance of the respective surface energies at the interface, which is described below. 
Adhesion Energy Barrier: This is the crux of the adhesion/detachment process. The proposed model for bonding two metal surfaces under KEM conditions is that the incident normal force be greater than the resistive surface-energy force.

$$
\sigma_{\mathrm{A}}(\mathrm{t}) \mathrm{A}_{\mathrm{c}}(\mathrm{t})>\mathrm{F}_{\mathrm{ad}}(\mathrm{t})
$$

where $\mathrm{F}_{\mathrm{ad}}=4 \pi \mathrm{R} \gamma_{\mathrm{o}}\left(\mathrm{W}_{\mathrm{A}} \mathrm{m}_{\mathrm{W}_{\mathrm{B}}}\right)^{1 / 2}$

$\sigma_{\mathrm{A}}:$ Incident normal stress at interface

$\sigma_{\mathrm{ad}}:$ Adhesion barrier between materials A and B;

$\mathrm{R}$ : Local radius of curvature at interface;

$\mathrm{A}_{\mathrm{c}}$ : Effective contact surface area;

$\gamma_{0}:$ Effective contact surface area;

$\sigma_{\mathrm{A}}$ : Reference surface energy;

$\mathrm{W}_{\mathrm{A}}$ : Ratio of surface energy of material A: $\gamma_{\mathrm{A}} / \gamma_{\mathrm{O}}$;

$\mathrm{W}_{\mathrm{B}}$ : Ratio of surface energy of material $\mathrm{B}: \gamma_{\mathrm{B}} / \gamma_{\mathrm{O}}$;

$\mathrm{m}$ : $\quad$ Impact parameter for material A;

$\mathrm{n}$ : Impact parameter for material B

When the incident force represented by the normal stress and the contact area at the interface is greater than the resistive force on the right side of the above equation (composed of the surface energies of incident material A and the target material B), adhesion will take place. On the other hand, when the above criterion is not satisfied, there will be no bonding or even detachment. It is thus important in numerical modeling to keep track of this criterion at every interface as a function of time following the impact of material A on the target material B.

Numerical Analysis: Numerical analyses have been conducted for metal particles impinging on metal targets at various impact velocities. At high velocities, in the range of $500 \mathrm{~m} / \mathrm{s}$ or greater, the calculated results show sizable deformation of the incident particles as well as the target material and subsequent increase in the contact surface area and adhesion at the interface. Examination of test samples reveal the same deformation and lateral displacement, suggesting the validity of the proposed model for metal-bonding phenomena under high-velocity impact under room conditions. 


\section{SUMMARY}

To theoretically model the underlying metal-coating phenomena when metal particles impact a metal surface at high velocities under room temperature conditions.

The physical processes involved in the novel metal-coating process called Kinetic Energy Metallization (KEM) have been theoretically and numerically analyzed. A bonding model between the incident and the target metals has been proposed and preliminary numerical results agree reasonably well with the laboratory-obtained metal samples and suggest promise of validity for the present model. However, to put the proposed bonding model on a firmer basis further numerical effort is needed to be carried for various metals and operating conditions. 


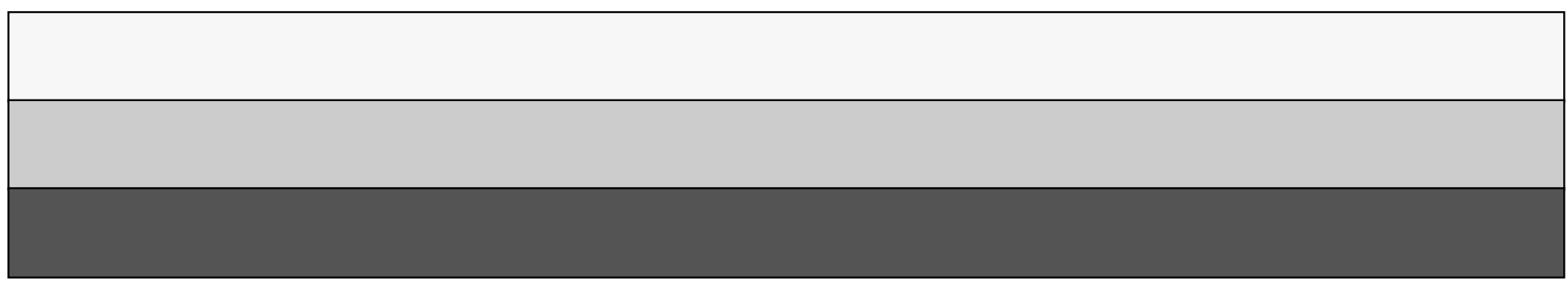

